\title{
Evaluation of Myocardial Tissue Doppler Echocardiography as a Predictor for Recovery of Left Ventricular Function after Percutaneous Coronary revascularization for Patients with Coronary Artery Disease
}

\author{
Ahmed Youssef ${ }^{1}$, Ahmed Ali ${ }^{1}$, Ahmed Salah $^{1}$, and Mohamed Oraby ${ }^{1}$ \\ ${ }^{1}$ Suez Canal University Faculty of Medicine
}

May 8, 2020

\begin{abstract}
Background: Trials postulate that analysis of pre-ejection velocities is closely sensitive to blood supply. Tissue velocities declines with reduced regional perfusion and recover on reperfusion. Accordingly, tissue doppler imaging (TDI) can predict myocardial function recovery after revascularization. Purpose: To assess the value of Tissue Doppler Imaging echocardiography in predicting recovery of myocardial function after percutaneous coronary revascularization in patients with coronary artery disease (CAD). Methods: 27 patients with CAD based on coronary angiography were prospectively studied. Echocardiography with 2D measurements, global systolic function and longitudinal myocardial velocities; (IVCPv, S wave, AT, IVCT, CT and IVRT) of the affected segments were recorded 24 hours before revascularization and 6 months after revascularization. Functional recovery was defined as increase in LVEF by [?]5 \%. Results: All patients underwent PCI. Most of TDI parameters changed significantly with revascularization, however only mean IVCPv and $\mathrm{S}$ wave of dysfunctional segments at rest correlated significantly with recovery of global systolic function. Mean IVCPv $>2.8 \mathrm{~cm} / \mathrm{sec}$ and mean $\mathrm{S}$ wave $>4.6 \mathrm{~cm} / \mathrm{sec}$ at baseline are an objective indicator of global systolic function recovery with sensitivity, specificity and accuracy for IVCPv $(85 \%, 70 \%, 79 \%$ respectively) and PPV was estimated to be $80 \%$ ( $\mathrm{AUC}=0.789, \mathrm{CI}=0.603-0.975, \mathrm{P}$ value $=0.02$ ), while for $\mathrm{S}$ wave $(87 \%, 77 \%, 83 \%$ respectively) and PPV was $87 \%$ (AUC=0.833, $\mathrm{CI}=0.664-1.000, \mathrm{P}$ value=0.007). Conclusions: The resting pattern of IVCPv \& S wave by TDI accurately predicts the recovery of global systolic function with high PPV but not the regional function after revascularization in patients with CAD.
\end{abstract}

\section{Hosted file}

Full Manuscript.pdf available at https://authorea.com/users/319630/articles/449335evaluation-of-myocardial-tissue-doppler-echocardiography-as-a-predictor-for-recoveryof-left-ventricular-function-after-percutaneous-coronary-revascularization-for-patientswith-coronary-artery-disease 

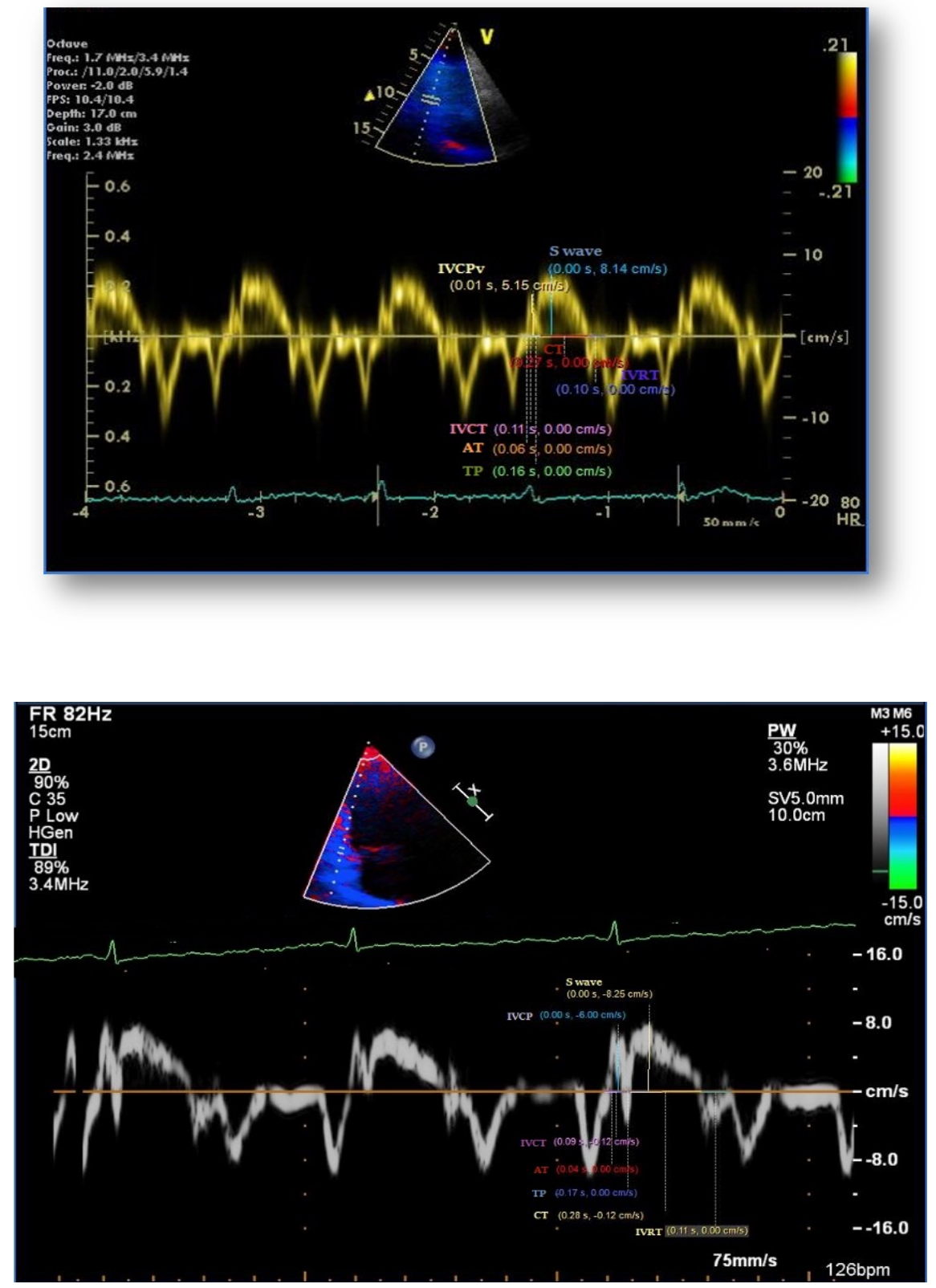